\section{A CASE OF CEREBRAL CHOLESTEATOMA}

\section{BY \\ I. R. S. GORDON, M.B.}

The following case seems to be unusual enough to merit description.

\section{Case Report}

The patient, a man aged 36 , was admitted to hospital in March, 1940, complaining of headaches, attacks of giddiness, and a right-sided hemiplegia. He was quite well until 1933, when he began to suffer from attacks of giddiness, after which he could hear and see objects but was unable to understand what was said to him. These attacks continued to occur more often until in 1936 they recurred about once a month, and were associated with frequent headaches, both frontal and temporal. At this time there were no visual defects or loss of consciousness, his blood pressure was $125 / 90$, and no abnormal physical signs were found. His headaches were controlled by 10 grains of aspirin. His case was diagnosed as petit mal. In 1937 he was admitted to hospital with a left-sided mastoiditis. A mastoidectomy was performed. After this his condition showed a temporary improvement, but in 1939 he began to deteriorate, and developed clumsiness, with progressive weakness of the right side of the face, the right arm, and the right leg. There was no visual defect or vomiting.

Examination.-On admission the findings were: Constricted pupils, equal, but reacting only sluggishly to light and accommodation; lack of expression and weakness over the whole of the right side of the face ; slight deafness in the left ear; power and co-ordination defective in the right arm and leg as compared with the left side; tendon jerks in the right arm and leg exaggerated; right abdominal reflexes absent; plantar reflexes extensor on the right, flexor on the left, side; temperature $97.6^{\circ} \mathrm{F}$.; pulse 80 ; the optic disks were both normal ; forced grasping not present; speech normal; mental state normal apart from a slightly defective memory and some lack of a sense of proportion.

Investigations.-On lumbar puncture C.S.F. fluid, clear, colourless, and without clot, was obtained under a pressure of $190 \mathrm{~mm}$. of water; cells, two lymphocytes per c.mm.; albumin $30 \mathrm{mg}$., sugar $40 \mathrm{mg}$., and chlorides $710 \mathrm{mg}$. per $100 \mathrm{c.cm}$. A blood count showed 5,900,000 red cells per c.mm., 112\% haemoglobin (Haldane), and 8,000 white cells ; the blood sedimentation rate was within normal limits. The Wassermann test gave a doubtful result, and the Meinicke reaction was negative. A radiograph of the skull showed no evidence of neoplasm; but a special radiograph of the mastoid processes revealed sharply defined translucent areas replacing the left mastoid air cells, with an adjacent sclerosis, suggesting postoperative translucency or possibly cholesteatoma; the right side was normal. An electro-encephalogram disclosed abnormal delta waves, frequency $2 \frac{1}{2}$ to 3 per second, accentuated by overbreathing-indicative of a slowly growing space-occupying lesion (neoplasm, abscess, or granuloma) localized to the left temporal region.

Course.-On April 8 and again on April 12 the old mastoidectomy wound was explored, and fluid was obtained from beneath the dura $-20 \mathrm{c.cm}$. on the first occasion and $90 \mathrm{c.cm}$. on the second. This fluid was pale yellow and translucent, with flaky shimmering crystals. It was reported by the pathologist to contain numerous epithelial scales and cholesterol crystals but no pus cells or micro-organisms, and was described as similar to that obtained from a branchial cyst. Three days later the patient developed a pyrexia of $103^{\circ} \mathrm{F}$., headache, neck rigidity, and a positive Kernig's sign. The cerebrospinal fluid was now turbid with numerous polymorphs, and Type I meningococci were grown. In spite of sulphapyridine therapy his condition slowly deteriorated, and he died on April 22.

Post-mortem Examination.-A necropsy was performed, and besides evidence of a diffuse purulent leptomeningitis, a tumour $8 \mathrm{~cm}$. in diameter was found. This appeared to replace the left temporal lobe and a large portion of the left frontal lobe, to form part of the wall of the left lateral ventricle, and to compress the right temporal and frontal lobes. It was soft and friable, and appeared to be encapsulated in some parts, though it was difficult to say macroscopically whether the tumour compressed or invaded the brain tissue.

Microscopical examination revealed that the soft inner portion of the tumour consisted mainly of squamous epithelial cells and cholesterol crystals. From sections of the edge of the tumour it was seen that the boundary was a thin layer of stratified squamous epithelium. The zone external to this consisted of compressed nervous tissue and showed a heavy fibrillary gliosis with some thickening of the walls of the blood vessels.

\section{Commentary}

There seems little doubt that this tumour was a cholesteatoma, the histological report agreeing well with previous descriptions of this type of tumour, especially in the presence of an external limiting zone of stratified squamous epithelium. Unusual features are the large size of the tumour and the late development and mild character of the clinical manifestations.

It is generally thought that cholesteatomata arise from embryonic cell inclusions of an ectodermal origin, possibly in connexion with the branchial clefts. Some authors, however, have suggested that they arise-especially those of the middle ear-by metaplasia of the columnar epithelium of that cavity secondary to chronic inflammation (Critchley and Ferguson, 1928). In the latter connexion it is perhaps of interest that in this case mastoiditis was present, and the clinical history would seem to indicate an early involvement of the inner ear.

The situation in which the tumour was found accounts for the relatively slight clinical manifestions, in spite of the size and extent of the growth. The histological examination seems to show that the brain was grossly compressed rather than invaded by the tumour. The left frontal and temporal lobes are silent areas, and it is characteristic of a tumour in this position that the first localizing sign should be a right hemiplegia and should appear so late after the onset of the patient's illness.

Acknowledgment must be paid to Prof. Golla and Dr. Grey Walters for the preparation of the encephalogram and to Dr. R. M. Norman for the preparation and examination of the tumour sections.

REFERENCE

Critchley, M., and Ferguson, F. R. (1928). Brain, 51, 334.

Skim-milk, perhaps because of a popular old advertisement, is a rather opprobrious term, and the prejudice against this product in America is such that according to the U.S. Department of Agriculture only about $12 \%$ of the skim-milk produced is used in the manufacture of dairy products. In a paper by Mr. J. S. Abbott at the sixty-ninth annual meeting of the American Public Health Association it was urged that the misuse of skim-milk constitutes an enormous economic waste. It contains all the essentials of whole milk except the milk fat and fat-soluble vitamins, and it even contains a certain amount of each of these, though not so much as whole milk. The Nutrition Committee of the League of Nations stated that, pint for pint, skim-milk contains more calcium, phosphorus, iron, and protein (though, of course, fewer calories) than whole milk, and is much cheaper. It is a good foodstuff for animals, but to feed it to pigs is unsound economics because it requires 10 pounds of the food nutrients in skim-milk to produce 1 pound of food nutrients in the form of pork. Industry and legislative effort to create a market for this wholesome foodstuff, says the author of the American paper, would be in the interest of consumers and dairy farmers alike, and there ought not to be any restrictions or discriminations against compounding skim-milk with other foodstuffs for use as human food in the manufacture of food products that supply a want of the people and that can be produced economically to advantage. 